\title{
Base Nacional Comum Curricular: \\ ponto de saturação e retrocesso na educação
}

Common National Curricular Base:

a saturation and setback point in education

Base Nacional Común Curricular:

punto de saturación y retroceso en la educación

FERNANDOL. CÁSSIO*

Universidade Federal do ABC, Santo André- SP, Brasil.

RESUMO: A Base Nacional Comum Curricular (BNCC) éhoje o centro gravitacional das políticas do Ministério da Educação. Neste texto procuro construir a tese de que a BNCC representa um grave retrocesso na educação brasileira, ponto de saturação de um projeto de centralização curricular iniciado há mais de 20 anos, com os Parâmetros Curriculares Nacionais. Também exploro alguns elementos recentes do processo de "implantação" da Base, que ocorre simultaneamente dentro e fora do Estado, sublinhando que a complexidade desses processos desafia eventuais ações de resistência organizada à BNCC.

Palavras-chave: Base Nacional Comum Curricular. Políticas educacionais. Plano Nacional de Educação. Parâmetros Curriculares Nacionais. Currículo.

\begin{abstract}
The National Curricular Common Core (BNCC)is today the gravitational center of the policies of the Ministry of Education. In this text, I try to build the thesis that the BNCC represents a serious setback in Brazilian education, a saturation point of a curricular centralization project started more than 20 years ago, with the National Curricular Parameters. I also explore some recent elements of the Foundation's "implantation" process, occurring simultaneously inside
\end{abstract}

* Professor adjunto da Universidade Federal do ABC. É doutor em Ciências (Química) pela Universidade de São Paulo. Possui bacharelado em Ciências Moleculares e licenciatura em Química pela Universidade de São Paulo. E-mail:<fernando.cassio@ufabc.edu.br>. 
and outside the state, emphasizing that the complexity of these processes challenges subsequent actions of organized resistance to BNCC.

Keywords: National Curricular Common Base. Educational policies. National Education Plan. National Curricular Parameters. Curriculum.

RESUMEN: La Base Nacional Común Curricular (BNCC) es hoy el centro gravitacional de las políticas del Ministerio de Educación. En este texto procuro construir la tesis de que la BNCC representa un grave retroceso en la educación brasileña, punto de saturación de un proyecto de centralización curricular iniciado hace más de 20 años, con los Parámetros Curriculares Nacionales. También exploro algunos elementos recientes del proceso de "implantación" de la Base, que ocurre simultáneamente dentro y fuera del Estado, subrayando que la complejidad de esos procesos desafía eventuales acciones de resistencia organizada a la BNCC.

Palabras clave: Base Nacional Común Curricular. Políticas educacionales. Plan Nacional de Educación. Parámetros Curriculares Nacionales. Currículo.

\section{Mais uma política de currículo?}

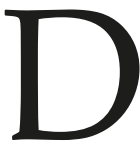

esde que comecei a fazer falas públicas e a escrever sobre a Base Nacional Comum Curricular (BNCC), e agora estimulado pela proposta deste dossiê, tenho pensado de que forma a BNCC poderia ser considerada um retrocesso na educação brasileira. Tentarei, nas breves páginas que seguem, ensaiar algumas respostas a isso. ${ }^{1}$

A BNCC é, antes e acima de tudo, uma política de centralização curricular. ${ }^{2}$ Define os objetivos de aprendizagem - eufemisticamente denominados "direitos de aprendizagem" $^{\prime 3}$ - que devem orientar o trabalho pedagógico em todas as escolas brasileiras e em todas as etapas da educação básica (da educação infantil ao ensino médio). Obrigatória e com repercussão nacional a Base tem implicações diretas nas políticas estatais de compra e distribuição de materiais didáticos e de formação inicial e continuada de professores, além de influir nas (e de ser influenciada por) avaliações em larga escala. A BNCC já vem induzindo uma cadeia de reformas nas redes estaduais e municipais de ensino, onde novas políticas de currículo estão sendo formuladas a toque de caixa, a despeito de a Base para o ensino médio não ter sido sequer aprovada. 
Em primeiro lugar, é preciso avaliar em que medida a existência da BNCC representa uma mudança substantiva no cenário de centralização curricular das entidades subnacionais. Todos os estados e muitos grandes municípios já possuem referenciais curriculares próprios, devidamente acompanhados por avaliações externas censitárias e, eventualmente, por políticas de bonificação a partir dos indicadores de performance oriundos das avaliações. A grande capilaridade das políticas de avaliação em larga escala no Brasil, por seu turno, é evidenciada no extenso levantamento de Bauer et al. (2015), a partir de informações de 4.309 municípios brasileiros, que revelou que 1.573 deles possuíam sistemas de avaliação próprios em 2014, ao passo que 908 manifestavam interesse em construir os seus.

Também não se pode subestimar o papel do Programa Nacional do Livro Didático (PNLD) como política de currículo, haja vista a infinidade de trabalhos que mostram que os livros didáticos distribuídos pelo governo federal influenciam não apenas a organização do trabalho pedagógico nas escolas, mas o modo como muitos professores e professoras concebem a estrutura das disciplinas. O PNLD foi instituído em 1985 (Decreto n. 91.452/1985), e em meados dos anos 1990 sofreu uma guinada na esteira do movimento de Reforma do Estado brasileiro (GARCEZ, 2013), quando se consolidou - com algumas variações - o atual modelo de alocação de recursos, de avaliação, de compra e de distribuição de livros didáticos pelo Ministério da Educação (MEC). Não por acaso, remonta aos mesmos anos 1990 a formulação dos Parâmetros Curriculares Nacionais (PCN).

Uma investigação recente com as contribuições escritas à consulta pública da primeira versão da BNCC (set. 2015) mostrou que um grande número de críticas ao texto da Base se fundamenta em sumários de livros didáticos e em referenciais curriculares estaduais, sugerindo que grande parte da recepção negativa à Base observada na consulta repousa nas tensões entre o novo referencial curricular e as políticas de currículojá existentes, sejam os referenciais curriculares regionais seja o próprio PNLD (CÁSSIO \& SPINELLI JR., 2018). Também não é o "medo da novidade" que parece motivar as reações negativas ao texto da BNCC, pois nada do conteúdo da Base é propriamente estranho ao professorado. Na primeira versão da Base do ensino médio (set. 2015), em particular, as contribuições escritas sugeriam que a grande "inovação" da Base parecia ser justamente a falta de conteúdos (SPINELLI JR. \& CÁSSIO, 2017), depois agravada pela publicação de uma terceira versão (abr. 2018), que reteve apenas dois dos componentes curriculares das primeiras versões - Língua Portuguesa e Matemática -, alinhando-se com a Reforma do Ensino Médio iniciada em setembro de 2016, com a publicação da Medida Provisória n. 746 (depois convertida na Lei n. 13.415/2017).

Nenhum desses resultados chega a surpreender: a partir do protocolo de consulta pública individualizado e tendencioso disponibilizado pelo MEC (CÁSSIO, 2017), não é mesmo possível esperar um movimento de resistência massivo a uma homogeneização já incorporada como tradição curricular em muitas redes de ensino, ponderando-se 
ainda que o conjunto dos participantes da consulta não pode ser tomado como amostra representativa do professorado brasileiro (CÁSSIO \& SPINELLI JR., 2018).

As únicas conclusões seguras a que podemos chegar até aqui são: 1) que uma nova política de currículo não proverá soluções para problemas que as políticas anteriores não foram capazes de enfrentar; 2) que a BNCC entra em conflito com uma série de políticas de currículo (nacionais e regionais) já existentes e semelhantes a ela em suas inclinações centralizadoras. Contudo, isso não significa dizer que a BNCC é uma política de currículo igual a todas as demais.

\section{A radicalização de um projeto}

Como política de centralização curricular, a BNCC tem muitas semelhanças com seus congêneres regionais: as propostas curriculares de estados e de municípios. ${ }^{4}$ De saída, portanto, pode-se afirmar que a existência e a obrigatoriedade da nova Base não implicam a incorporação automática e uniforme do texto às práticas pedagógicas e aos cotidianos escolares, pois nenhuma proposta curricular estadual ou municipal, ainda que obrigatória, se manifesta da mesma forma em todo lugar. Com Alice Lopes (2015), considero vã a pretensão das políticas de currículo de eliminar os complexos processos discursivos que multiplicam as possibilidades de leitura e de tradução dos textos, e que tornam impossível normalizar o que acontece nas salas de aula.

Uma política curricular também não faz desaparecer as diferenças materiais entre as redes de ensino e nem as disputas que influenciam as tomadas de decisão locais. Como convencer milhares de municípios brasileiros com baixo poder arrecadatório de que a adoção da BNCC é mais importante para os seus sistemas de ensino do que a garantia de recursos mínimos para o funcionamento das escolas, como água filtrada e coleta de esgoto? Os contextos das redes de ensino, das escolas, das salas de aula e dos entornos escolares são, pois, inelimináveis por políticas curriculares de pendor centralizante.

Em um futuro hipotético, no qual um currículo nacional e comum seja capaz de uniformizar radicalmente as aprendizagens e experiências escolares de todos os estudantes do País, ele precisará obliterar dos processos educativos as relações entre as pessoas refundar aquilo que conhecemos por educação (BIESTA, 2016:18); quem sabe eliminando escolas, estudantes ou professores. Esse exercício distópico nos ajuda a perceber que, apesar de tudo aquilo que não é passível de controle, uma política de currículo como a BNCC não é de forma alguma inócua, pois mira justamente a transformação dos papéis de escolas, estudantes e professores - e das relações entre eles - nos processos educativos. A BNCC é a expressão de um projeto educacional para o País, e isso deveria nos preocupar.

Vejamos o caso de um projeto de centralização curricular já conhecido: o dos Parâmetros Curriculares Nacionais (PCN), publicados em meados dos anos 1990. Em um 
artigo da época, Antônio Flávio Barbosa Moreira denunciava uma série de problemas no processo de elaboração dos Parâmetros, que podem ser facilmente transportados para o atual contexto de crítica aos discursos que se hegemonizam em torno da BNCC: adesão acrítica a modelos curriculares estrangeiros, exclusão das universidades e sistemas de ensino do processo de construção do documento, contradição entre o detalhamento dos documentos e as especificidades das redes de ensino, etc. (MOREIRA, 1996:17). Moreira manifestava descrença quanto à incorporação dos PCN nas escolas, e defendia uma resistência "construtiva e coletiva" aos Parâmetros, e não "individualista", constituindo "mais uma atitude de comodismo que de rebeldia criativa" (MOREIRA, 1996:20). Apesar de um certo ceticismo no êxito dos PCN, provavelmente admitindo as limitações insuperáveis das políticas de centralização curricular, Moreira reconhecia que uma eventual extensão do mandato de Fernando Henrique Cardoso a partir de 1999 poderia representar a consolidação dos Parâmetros no bojo de um projeto educacional de longo prazo:

Estou certo, porém, de que dessa vez a luta vai ser dura. Livros didáticos, materiais instrucionais, ensino a distância, supervisão, avaliação das escolas, etc., buscarão colocar, ao longo do tempo, o professor no "caminho certo" e torná-lo, afinal, "competente" e "produtivo". Principalmente se a "reeleição" for negociada, como se anuncia (1996:20).

O grande empenho da União para implementar a BNCC pode ser comparado aos esforços envidados para emplacar os PCN naquele momento, embora estes não tenham conseguido se afirmar como base curricular obrigatória. No início dos anos 2000, Bonamino e Martínez reportavam que o MEC e o Conselho Nacional de Educação (CNE) estabeleceram uma relação de mútua omissão no tocante às questões curriculares no final da década de 1990, de forma que:

No caso do CNE, foi estabelecida uma metodologia para a elaboração das DCNs [Diretrizes Curriculares Nacionais] que declarou os PCNs não-obrigatórios, ao mesmo tempo em que buscava basear-se apenas na Constituição e na legislação educacional precedente.

No caso do MEC, as referências para a elaboração dos PCNs foram buscadas na legislação e em agentes externos ao sistema público de ensino fundamental, e sua estratégia consistiu em ignorar as DCNs sob responsabilidade do CNE (BONAMINO \& MARTÍNEZ, 2002:383).

Apesar de o projeto centralizador que previa a regulamentação dos PCN como base curricular obrigatória ter sido parcialmente freado pelo $\mathrm{CNE}$, ele não foi desarticulado por completo - um provável efeito da relação de mútua omissão descrita pelas autoras. Não se pode negar, com isso, que o projeto educacional disparado pelos PCN e epitomizado nas avaliações em larga escala frutificou no Brasil e ganhou capilaridade nas redes de ensino. É forçoso comparar a resistência "individualista" aos PCN, indesejada por Moreira em 1996, com a resistência individualista orientada pelas políticas curriculares 
vigentes na consulta pública da BNCC, 20 anos depois. No âmbito dos programas de formação docente nas universidades brasileiras, a linguagem das competências e dos padrões de aprendizagem - e a popularidade de autores como César Coll, Antoni Zabala e Philippe Perrenoud - são legados inquestionáveis do projeto curricular dos PCN.

Quando a pedagogia das competências apareceu pela primeira vez na BNCC, no texto da terceira versão (abr. 2017), a comparação entre os projetos educacionais da Base e dos PCN restou incontornável, sobretudo porque o grupo político que, no MEC, passou a se encarregar do processo de elaboração e implantação da BNCC após o impeachment de Dilma Rousseff é o mesmo que trabalhou na elaboração dos PCN décadas atrás.

A BNCC é o ponto de saturação das políticas de centralização curricular no Brasil, uma síntese das políticas de currículo brasileiras desde os PCN temperada com o linguajar dos common core de alguns países. ${ }^{5}$ Embora se possa argumentar que o golpe institucional de 2016 tenha importado mudanças substantivas à BNCC, sobretudo por conta da Reforma do Ensino Médio e da opção - influenciada por setores reacionários do governo Temer - de eliminar do texto da Base os temas considerados "polêmicos" (gênero, sexualidade, raça, desigualdades), a estrutura geral do documento aprovado pelo CNE (dez. 2017) é muito semelhante à das versões publicadas antes da mudança de governo. Isso coaduna com a avaliação de Elizabeth Macedo de que diferentes grupos políticos no Brasil têm se articulado em torno de demandas por "qualidade na educação", que se torna "um significante aparentemente esvaziado de sentidos e, por isso mesmo, capaz de condensar as diferentes demandas" (2016:9). A autora afirma que "uma múltipla rede de discursos vem construindo a hegemonia da ideia de que uma educação de qualidade (social) requer centralização curricular" (2016:11). A consequência disso é que o clamor por uma BNCC - via de realização dessa "qualidade na educação" - difunde-se por grupos de largo espectro político.

Por conta disso, desde 2015 a BNCC tem sido o ponto focal das políticas educacionais do governo federal, embora constitua apenas uma pequena parte do Plano Nacional de Educação 2014-2024 (PNE). ${ }^{6}$ Não sendo o objetivo deste texto oferecer uma análise das políticas propostas no PNE, detenho-me em notar que, a despeito da existência do Plano como aglutinador das políticas educacionais no Brasil, diversas políticas a ele vinculadas, e que deveriam ter sido implantadas em seus primeiros anos de vigência, têm sido ignoradas em favor da BNCC.

A secundarização do PNE no orçamento da União foi cimentada em agosto de 2017, quando Michel Temer vetou o artigo da Lei de Diretrizes Orçamentárias (LDO) que incluía, entre as prioridades do orçamento para 2018, o cumprimento das metas previstas no Plano. ${ }^{7}$ A BNCC tornou-se oficialmente o centro gravitacional das políticas do MEC: Reforma do Ensino Médio (Lei n. 13.415/2017), que dividiu o debate público da $\mathrm{BNCC}^{8}$ em duas fases; Política Nacional de Formação dos Profissionais da Educação Básica (Decreto n. 8.752/2016), que atrelou os programas de bolsas de iniciação à 
docência a ações de formação inicial calcadas na aplicação da BNCC; PNLD (Decreto n. 9.099/2017), cuja composição das equipes de avaliação é agora rigidamente controlada pelo MEC; e Política Nacional de Avaliação e Exames da Educação Básica (Decreto n. 9.432/2018), que traz um novo modelo de avaliação para a educação infantil - todas explicitamente atreladas à BNCC.

No artigo 3ํㅡㄹ da recém-aprovada LDO 2019, o PNE voltou a figurar como prioridade da administração pública federal para o próximo exercício (BRASIL, 2018a). Entretanto, o artigo 24, que dispunha que a alocação de recursos com vistas ao cumprimento das metas do PNE “deverá buscar a implantação do Custo Aluno-Qualidade Inicial (CAQi), nos termos da estratégia 20.6 do PNE" (BRASIL, 2018b), recebeu veto presidencial. A justificativa é que

Os referidos dispositivos restringem a discricionariedade alocativa do Poder Exe-
cutivo na implementação das políticas públicas, provocam aumento do montante
de despesas primárias com execuçãoo obrigatória e elevam, ainda mais, a alta rigi-
dez do orçamento, dificultando não apenas o cumprimento da meta fiscal, como
também do teto de gastos, estabelecido pela EC 95, e da Regra de Ouro, constante
do inciso III, do Art. 167 da Constituição (BRASIL, 2018b).

Em outras palavras, a inviabilização do cumprimento das estratégias do PNE relacionadas ao financiamento da educação (meta 20) torna sem efeito quaisquer afirmações no sentido de priorizar o PNE no orçamento público. Junto com o CAQi, a LDO 2019 obstaculiza uma série de outras metas do PNE que dependem do aumento do volume de recursos, como a política de salários, carreira, formação e condições de trabalho dos profissionais da educação (metas 15 a 18), e a melhoria da infraestrutura das unidades escolares (meta 7).

Os investimentos da União com vistas à elaboração e à implantação da BNCC são da ordem de alguns bilhões de reais (incluídas as ações de formação docente vinculadas à Base), bem inferiores aos $\mathrm{R} \$ 50$ bilhões necessários para a implementação imediata do CAQi (CAMPANHA, 2018:34), que por sua vez representam pouco mais de $2 \%$ da arrecadação de impostos no Brasil em 2017. A concentração de esforços para a implantação da BNCC, portanto, não se dá exclusivamente por uma crença dos reformadores na sobredeterminação da qualidade da educação pelas políticas curriculares. Ela é, primeiramente, uma opção econômica: a implantação da BNCC custará muito menos para a União do que a efetivação dos investimentos preconizados pelo PNE. Em segundo lugar, a Base franqueia um sem-número de oportunidades de negócio para os agentes privados interessados naquilo que dela deriva: novas metodologias para avaliações em larga escala, produção de materiais didáticos, programas de formação docente de baixo custo e flexibilização curricular no ensino médio (especialmente nos nichos da educação profissional e tecnológica e da educação a distância).

As experiências de implementação de políticas de currículo acumuladas nas últimas duas décadas hoje orientam os implementadores da BNCC na direção de radicalizar o 
programa homogeneizador (e, de certo modo, inconcluso) dos PCN. Ao mesmo tempo em que reconhecem as limitações das políticas de currículo, os implementadores da Base não as tomam como insuperáveis (deixando espaços para múltiplas possibilidades de elaboração). Eles creem na possibilidade de realizar a BNCC como uma superpolítica educacional, bastando para isso adotar melhores estratégias do que as empregadas no passado. Opondo-se a essa visão, Gert Biesta pontua que

Apesar das tentativas de muitos de transformar a educação em uma tecnologia causal (geralmente baseada na ideia de que só precisamos de mais pesquisas para descobrir e controlar todos os fatores que determinam a aprendizagem), o simples fato de que (...) a educação é um sistema aberto e recursivo - mostra que é a própria impossibilidade de uma tecnologia educacional o que torna a educação possível (BIESTA, 2016:34-35).

Um corolário disso é que toda tentativa de reduzir a educação a uma tecnologia causal representa uma ameaça à própria educação. Os implementadores da BNCC vendem a ideia de que é possível saber quais são os botões que, uma vez apertados, garantirão um futuro glorioso para a educação brasileira. Por suas veleidades de controle, a Base é uma tecnologia causal por excelência. Eis uma forte razão para temê-la como um retrocesso na educação e, sobretudo, para lutar contra ela.

\section{Muito além dos governos}

No recém-realizado $2^{\circ}$ Congresso Internacional de Jornalismo de Educação foram disponibilizados diversos materiais produzidos por bancos, editoras e fundações empresariais que patrocinavam o evento: ${ }^{9}$ relatórios de atividades, folders de projetos, compêndios de dados, estudos encomendados, white papers, etc. Em meio a dezenas de brindes, destacava-se um singelo caderno de anotações, com não mais que 20 folhas, oferecido pela Fundação Lemann, a mais rica das fundações empresariais que atuam na educação brasileira. Na capa azul, acima do logotipo do patrocinador, lia-se uma única frase em letras capitais: "queremos mudar o Brasil".

A atuação da Lemann em favor da BNCC, marcadamente como cofundadora, em 2013, do Movimento pela Base Nacional Comum (PERONI \& CAETANO, 2016; CÁSSIO, 2018), é um exemplo eloquente de que a implantação de uma política como a BNCC não se dá apenas no domínio dos governos. Nos últimos anos, Stephen J. Ball tem publicado preciosos trabalhos de análise de políticas que distinguem "governança, realizada por meio da 'autoridade informal' de redes diversas e flexíveis, e governo, executado através de hierarquias ou especificamente dentro das administrações e por métodos burocráticos" (BALL \& JUNEMANN, 2012:3). Ball utiliza as ideias de governança e de rede como ferramentas para investigar processos de tomada de decisão e de implementação de 
políticas educacionais, cada vez mais diluídos em arranjos complexos e descentrados que incluem o Estado e diversos atores da sociedade (BALL, 2007; 2012).

Macedo também tem recorrido à noção de rede de Ball como recurso metodológico, em articulação com a teoria do discurso de Ernesto Laclau e Chantal Mouffe, para "entender a manutenção (ou a hegemonia) de um discurso em defesa da centralização curricular nas recentes políticas no Brasil" (MACEDO, 2016:11). Ela mapeou e percorreu algumas "rotas" na rede de parceiros privados da União Nacional dos Dirigentes Municipais de Educação (Undime), do Conselho Nacional de Secretários de Educação (Consed), do CNE e do MEC na definição da BNCC (MACEDO, 2014), e concluiu que a participação da Fundação Lemann e de outras organizações da "filantropia 3.0" (BALL, 2012) nesse processo "visa à produção de uma narrativa hegemônica sobre o que é qualidade na educação e sobre como atingi-la. O que está expulso dessa narrativa, o seu exterior constitutivo, é a noção de que a educação é um bem público e, como tal, precisa ser gerido" (MACEDO, 2014:1545).

Em um trabalho mais recente, Avelar e Ball (2017) tomaram o Movimento pela Base Nacional Comum como modelo para investigar o que denominam processos de heterarquização do Estado. "Heterarquia é uma forma organizacional [localizada] em algum lugar entre a hierarquia e uma rede, baseada em diversas conexões verticais e horizontais que permitem que diferentes elementos do processo de políticas cooperem (e/ou entrem em competição)" (BALL \& JUNEMANN, 2012:138). Os achados de Macedo (2014) e de Avelar e Ball (2017) são convincentes em mostrar que essas redes de políticas são, além de dinâmicas, abertas. Macedo defende que é justamente "esse 'limite' que torna a noção [de rede] potente para a análise das políticas contemporâneas, caracterizadas por uma multiplicidade de demandas e agentes políticos que, ao invés de assumirem a forma de equivalência, são topológicas"' (2016:10).

Uso esses trabalhos para sublinhar que o processo de "implementação" da BNCC não se encerra nas esferas governamentais, ideia sedimentada na literatura educacional mas que está longe de ser óbvia na maior parte das frentes de luta contra a BNCC e outras reformas "educacionais autoritárias". Na audiência pública sobre a Base do ensino médio ocorrida em São Paulo (8 jun. 2018), e formalmente cancelada pelo CNE em vista da ocupação do plenário por professores e secundaristas, os múltiplos oradores que se revezavam nos megafones protestavam contra Michel Temer, o MEC, o CNE e alguns de seus membros. Praticamente não se ouviu manifestações de contestação às fundações empresariais que, na linha de frente da "implementação" da BNCC, estavam na plateia para defender a Base.

É um tanto irônico que a matéria de imprensa mais abalizada sobre o cancelamento da referida audiência pública tenha sido produzida pela revista Nova Escola, ${ }^{10}$ principal escoadouro das ações de comunicação da Fundação Lemann em prol da BNCC. Fundada por Victor Civita em 1986, a revista consolidou sua marca no meio docente em função de 
contratos de assinaturas governamentais da Editora Abril, que durante anos garantiram a distribuição da revista impressa em milhares de escolas públicas. Tendo a Fundação Lemann como mantenedora desde 2016, o plano de negócio de Nova Escola foi reorientado: a revista tem funcionado como uma plataforma de advocacy das agendas políticas da Lemann, notadamente as da BNCC. A "revista" tem produzido um grande volume de matérias e posts favoráveis à Base e, nos últimos meses, se dedicado ao recrutamento de grupos de professores para a produção de planos de aula e sequências didáticas para a aplicação da BNCC nas escolas: os chamados "times de autores". Com isso a Lemann enceta uma operação de "entrega direta" da BNCC ao professorado brasileiro via redes sociais como Facebook, Instagram e Twitter.

Em março de 2017, a Fundação Lemann formalizou uma parceria com o Google. org para a criação de uma plataforma digital "que oferecerá milhares de planos de aulas digitais, vídeos e outros materiais para ajudar professores de todo o País a criar experiências de aprendizado mais ricas para seus estudantes", prometendo apoiar mais de "um milhão de professores" e atingir áreas de baixa conectividade. ${ }^{11}$ Para se ter uma ideia da dimensão do projeto, o Censo Escolar 2017 informa que existem quase 2,2 milhões de professores atuantes na educação básica no Brasil. Em 2018, a Lemann e o Banco Nacional de Desenvolvimento Econômico e Social (BNDES) anunciaram um aporte de R\$ 30 milhões para "levar, até 2024, internet de alta velocidade e assegurar a inserção tecnológica como ferramenta pedagógica a todas as escolas públicas".${ }^{12}$ Se a baixa conectividade em certas regiões do Brasil representa um risco para o projeto de distribuição da BNCC via planos de aula digitais, a mais nova articulação entre a Lemann e o BNDES consubstancia a avassaladora expansividade das redes de políticas descritas nos trabalhos que mencionei anteriormente.

Não tenho dúvidas de que a esmagadora maioria dos materiais de propaganda da BNCC que hoje atingem o professorado brasileiro não provém do MEC ou das redes de ensino, mas dos agentes privados que constelam estas intrincadas redes de políticas. Partindo do exemplo limitado da minha própria timeline no Facebook, onde acompanho dezenas de fundações empresariais, nos meses de junho e julho de 2018 fui exposto a uma grande quantidade de posts como:

10 COMPETÊNCIAS gerais da BNCC: Aprenda online a ganhe seu certificado

Este curso online e gratuito tem apenas duas horas e vai ajudar vocês e suas escolas a entenderem tudo sobre as competências gerais da Base Nacional Comum Curricular. Vamos nessa? (grifos no original)

Trata-se de um curso organizado pela Fundação Lemann e a revista Nova Escola, em parceria com o Instituto Inspirare e o Movimento pela Base Nacional Comum. Este último, por sua vez, vem disseminando uma série de "dicas" para o "alinhamento" dos currículos regionais às competências e habilidades "determinadas" pela BNCC. Em 
agosto de 2018, o conglomerado educacional Somos Educação - que não ainda não aparecia nas redes mapeadas por Macedo (2014) e por Avelar e Ball (2017) -, realizou uma palestra aberta em São Paulo intitulada "BNCC na prática". Adquirida em 2018 pelo grupo Kroton, a Somos Educação é proprietária das editoras Ática, Saraiva e Scipione, que juntas receberam $\mathrm{R} \$ 454,16$ milhões do Fundo Nacional de Desenvolvimento da Educação (FNDE) a título de aquisição de livros didáticos, mais de 1/3 do total dos valores negociados para o PNLD (ensino fundamental e médio) em 2017.13

A brevidade deste artigo me impede de fazer um mapeamento dessa rede e de percorrer algumas de suas rotas. Não pretendo, dessa forma, afirmar que as agendas da Fundação Lemann determinam o movimento mais amplo de "implementação" da BNCC, pois nas "relações público-privadas opacas, torna-se um desafio, quando não impossível, identificar com precisão o papel desempenhado por diferentes atores políticos, delimitando suas responsabilidades" (AVELAR \& BALL, 2017:8). Atento igualmente para a advertência de Macedo (2016) de que é preciso ter cuidado com a "sinédoque neoliberal", que pode nos levar a produzir uma leitura determinista da política.

Apesar disso, estou convencido de que a Fundação Lemann acredita na possibilidade de uma implementação radicalmente capilar (e mesmo paraestatal) da BNCC, e que o seu projeto para a educação brasileira é, como o seu slogan anuncia, um projeto nacional. Atuando por dentro (Undime, Consed, BNDES) ou por fora do Estado (Google. org e outros parceiros), o papel desempenhado pela Lemann neste vasto movimento de "implementação" da BNCC encontra muitos paralelos com a atuação da Fundação Bill and Melinda Gates na implantação dos Common Core State Standards dos Estados Unidos (HURSH, 2016), tema intrigante para os interessados nos arranjos reticulares entre governos, a filantropia 3.0 e as reformas educacionais em curso no Brasil.

Tudo isso, por fim, serve para nos alertar de que qualquer programa de luta contra a BNCC que se pretenda consistente deve considerar que a sua "implementação" é um processo complexo que se espraia para muito além do Estado e dos governos.

\section{A BNCC como retrocesso democrático}

Procurei argumentar que a experiência acumulada na implantação dos PCN e de outras políticas de currículo dos últimos anos hoje auxilia os implementadores da BNCC na reinvenção das tentativas de "controlar o que não pode ser controlado" (LOPES, 2015:456). Ainda que eu me convença de que, no final das contas, a BNCC será incapaz de teleguiar corações e mentes nas escolas brasileiras, a voracidade de sua "implementação", com a utilização deliberada de tecnologias da informação e da comunicação para a disseminação da Base (para citar apenas um elemento dessa voracidade), se afigura como uma visão assustadora do futuro da educação brasileira, em que processos 
de substituição tecnológica implicam não apenas a precarização e o esvaziamento do trabalho docente (BARRETO, 2016), mas a erradicação das relações que caracterizam a educação como projeto coletivo e, por conseguinte, dos conflitos, o que, "longe de nos proporcionar o horizonte necessário para o projeto democrático, é algo que o coloca em risco" (MOUFFE, 2016:48). Se recorro novamente ao exercício da ficção, não é por amor a um fatalismo apocalíptico, mas por compreender que a luta política não acaba nunca e que, por isso mesmo, é preciso cultivar a capacidade de diferenciar projetos. Afinal, o que é distopia para uns é utopia para outros.

Com isso quero dizer que considero a BNCC um retrocesso na educação e, mais do que isso, considero que a crença dos implementadores da Base na viabilidade de seu projeto uniformizador - a ponto de conceber estratégias cada vez mais sofisticadas para realizá-lo - é uma ameaça concreta a projetos educacionais democráticos. Por isso mesmo, a insistência da propaganda - sobretudo governamental - em associar a BNCC a processos de participação social e a uma suposta igualdade de oportunidades educacionais só ratificam a necessidade de persuadir as pessoas daquilo que a Base efetivamente não é e nem será capaz de produzir.

Tentei mostrar que a "implementação" da BNCC vai muito além dos governos, o que dificulta ações de resistência organizada a ela. Embora, neste texto, eu tenha tomado como exemplo o extrato de uma leitura particular de implementação, a da Fundação Lemann, tenho discutido em outros lugares aspectos das ações de implementação da Base em âmbito governamental (CÁSSIO, 2017; 2018). A implementação da BNCC é um processo de leitura extremamente difícil, o que, na minha visão, tem a ver com as limitações de nossas próprias teorias políticas. Com a ajuda de Mouffe (2015; 2016), tenho me esforçado para lidar com a complexidade dos processos da política sem sucumbir à tentação das leituras planificadas e da reificação, mas reconheço que, ao postular a BNCC como "ponto de saturação", coloco-me perigosamente na beira do abismo determinista. Em defesa da imagem paroxística de "ponto de saturação" que utilizei, considero-a como um instantâneo, esquissado a partir do que sou capaz de enxergar neste momento.

A despeito do tom ensaístico do texto, quero realçar o caráter programático de minhas colocações, e daí a opção por afirmar a BNCC como um insidioso retrocesso na educação brasileira. A agenda de luta anunciada por Moreira (1996), no contexto da elaboração dos PCN, soa como um vaticínio para os dias de hoje. Se a opção de agora for empreender uma luta aberta contra a BNCC, tenho certeza de que ela será muito mais dura do que há 20 anos. Mas é preciso começar por algum lugar. Quando me perguntam o que fazer para lutar contra a Base, tenho respondido sem pestanejar: vamos começar defendendo as escolas e a nossa profissão.

Recebido em: 20/08/2018 e aprovado em: 07/10/2018 


\section{Notas}

1 Agradeço a Ana Paula Corti (IFSP), parceira de trabalho na Rede Escola Pública e Universidade (REPU), pela leitura atenciosa deste texto e pelos apontamentos levantados.

2 Nos termos tomados de Elizabeth Macedo $(2014 ; 2015 ; 2016)$, que tem produzido trabalhos de grande densidade sobre políticas de currículo e, mais recentemente, sobre a BNCC. Chamo política de centralização curricular toda política de homogeneização de currículos, não necessariamente nacional, que subsidie outras políticas (de material didático, de avaliação, de formação docente, etc.). Nessa categoria se enquadram a BNCC, a grossa maioria das propostas curriculares de estados e municípios e, em alguns sentidos, os Parâmetros Curriculares Nacionais (PCN).

3 Críticas a essa formulação podem ser encontradas em: Macedo (2015); Ximenes e Cássio (2017); Cássio (2018). Aqui parto do princípio de que aprendizagem não é educação, e de que uma das principais manifestações de insuficiência do debate mais propriamente pedagógico da BNCC é a "aprendificação" da linguagem da educação (BIESTA, 2016:5).

4 Considerando-se que esses projetos curriculares regionais, por sua vez, também podem ser "compreendidos como recontextualizações, traduções, híbridos políticos ou releituras das propostas nacionais" (LOPES, 2015:452), a saber, os Parâmetros e as Orientações Curriculares Nacionais que circulam no Brasil desde meados dos anos 1990.

5 Se nos PCN a inspiração era a reforma educativa espanhola, a BNCC é influenciada por políticas de centralização curricular de países como Estados Unidos, Reino Unido e Austrália.

6 A BNCC é mencionada nas estratégias 2.2 (ensino fundamental), 3.3 (ensino médio), 7.1 (qualidade do ensino) e 15.6 (formação de professores) do PNE (BRASIL, 2014).

7 Disponível em: <http://agenciabrasil.ebc.com.br/educacao/noticia/2017-08/ldo-retira-prioridade-para-cumprimento-do-plano-nacional-de-educacao>. Acesso em: 20 jul. 2018.

8 A exemplo dos novos editais da Universidade Aberta do Brasil (UAB), com cursos de licenciatura na modalidade EaD; do Programa Institucional de Bolsas de Iniciação à Docência (Pibid); e do novo Programa de Residência Pedagógica - lançados pela Capes (Coordenação de Aperfeiçoamento de Pessoal de Nível Superior).

9 O evento foi realizado pela Associação de Jornalistas de Educação (Jeduca) e ocorreu em São Paulo/SP, entre 6 e 7 de agosto de 2018. Patrocínio master: Fundação Lemann, Fundação Telefonica/Vivo, Instituto Unibanco, Instituto C\&A e Itaú BBA; patrocínio: Editora Moderna e Fundação Itaú Social; apoio: Associação Brasileira de Jornalismo Investigativo, Colégio Rio Branco, Fundação Maria Cecília Souto Vidigal, Canal Futura, Todos pela Educação, Missão Diplomática dos EUA e Escola de Dados.

10 Disponível em: <https://novaescola.org.br/conteudo/11851/bncc-audiencia-e-cancelada-apos-protesto-de-professores-e-estudantes>. Acesso em: 29 jul. 2018.

11 Disponível em: <https://fundacaolemann.org.br/noticias/plataforma-trara-conteudo-ligado-a-bncc >. Acesso em: 29 jul. 2018.

12 Do total, R\$ 10 milhões serão aportados pela Fundação Lemann e outros R \$ 20 milhões pelo BNDES. Disponível em: <www.infomoney.com.br/carreira/educacao/noticia/7396430/bndes-fundacao-lemann-anunciam-investimentos-milhoes-educacao-brasil>. Acesso em: 29 jul. 2018.

13 Dados disponíveis em: <www.fnde.gov.br/centrais-de-conteudos/publicacoes/category/35-dados-estatisticos?download=10072:pnld-2017-valores-de-aquisição-por-editora-ensino-fundamental-e-médio>. Acesso em: 20 jul. 2018. 


\section{Referências}

AVELAR, Marina; BALL, Stephen. Mapping new philanthropy and the heterarchical state: The Mobilization for the National Learning Standards in Brazil. International Journal of Educational Development, 2017. (no prelo)

BALL, Stephen J. Education plc: Understanding private sector participation in public sector education. New York: Routledge, 2007.

BALL, Stephen J. Global Education Inc. New policy networks and the neo-liberal imaginary. New York: Routledge, 2012.

BALL, Stephen J.; JUNEMANN, Carolina. Networks, new governance and education. Bristol, UK: The Policy Press, 2012.

BARRETO, Raquel Goulart. Entre a Base Nacional Comum Curricular e a avaliação: A substituição tecnológica no ensino fundamental. Educação \& Sociedade, Campinas: CEDES, v. 37, n. 136, p. 775791, 2016.

BAUER, Adriana; PIMENTA, Claudia Oliveira; HORTA NETO, João Luiz; SOUSA, Sandra Zákia Lian. Avaliação em larga escala em municípios brasileiros: o que dizem os números? Estudos em Avaliação Educacional, São Paulo: FCC, v. 26, n. 62, p. 326-352, 2015.

BIESTA, Gert J. J. Good Education in an Age of Measurement: Ethics, Politics, Democracy. New York: Routledge, 2016.

BONAMINO, Alicia; MARTÍNEZ, Silvia Alícia. Diretrizes e Parâmetros Curriculares Nacionais para o Ensino Fundamental: A participação das instâncias políticas do Estado. Educação \& Sociedade, Campinas: CEDES, v. 23, n. 80, p. 368-385, 2002.

BRASIL. Lei n. 13.005, de 25 de junho de 2014. Aprova o Plano Nacional de Educação (PNE) e dá outras providências. Disponível em: <www.planalto.gov.br/CCIVIL_03/_Ato2011-2014/2014/Lei/ L13005.htm>. Acesso em: 20 jul. 2018.

Lei n. 13.707, de 14 de agosto de 2018a. Dispõe sobre as diretrizes para a elaboração e execução da Lei Orçamentária de 2019 e dá outras providências. Disponível em: <www.camara.leg.br/ internet/comissao/index/mista/orca/ldo/LDO2019/Lei_13707/Texto_Lei.pdf >. Acesso em: 15 ago. 2018.

. Mensagem n. 449, de 14 de agosto de 2018b. Disponível em: <www.camara.leg.br/ internet/comissao/index/mista/orca/ldo/LDO2019/Lei_13707/msg_veto.pdf>. Acesso em: 15 ago. 2018.

CAMPANHA NACIONAL PELO DIREITO À EDUCAÇÃO. O CAQi e o CAQ no PNE: Quanto custa a educação pública de qualidade no Brasil? São Paulo: Campanha Nacional pelo Direito à Educação, 2018. Disponível em: <www.custoalunoqualidade.org.br/pdf/quanto-custa-a-educacao-publica-dequalidade-no-brasil.pdf $>$. Acesso em: 8 jun. 2018.

CÁSSIO, Fernando. Participação e participacionismo na construção da Base Nacional Comum Curricular. Nexo Jornal, São Paulo, 02 dez. 2017. Disponível em:<www.nexojornal.com.br/ ensaio/2017/Participação-e-participacionismo-na-construção-da-Base-Nacional-Comum-Curricular>. Acesso em: 20 mai. 2018.

CÁSSIO, Fernando. Introdução: Existe vida fora da BNCC? In: CÁSSIO, Fernando; CATELLI JR., Roberto (Org.). Base Nacional Comum Curricular. São Paulo: Ação Educativa, 2018. (no prelo) 
CÁSSIO, Fernando; SPINELLI JR., Ronaldo. O encontro entre a BNCC e os professores de Química, ou Centralização curricular e a falácia do professor malformado. In: CÁSSIO, Fernando; CATELLI JR., Roberto (Org.). Base Nacional Comum Curricular. São Paulo: Ação Educativa, 2018. (no prelo)

GARCEZ, Fernando. A revitalização da política de livro didático no Brasil: Regular e avaliar para qualificar. Jornal de Políticas Educacionais, Curitiba: UFPR, v. 7, n. 13, p. 47-53, 2013.

HURSH, David W. The end of public schools: The Corporate Reform Agenda to Privatize Education. New York: Routledge, 2016.

LOPES, Alice Casimiro. Por um currículo sem fundamentos. Linhas Críticas, Brasília: UnB, v. 21, n. 45, p. 445-466, 2015.

MACEDO, Elizabeth. Base Nacional Comum para currículos: Direitos de aprendizagem e desenvolvimento para quem? Educação \& Sociedade, Campinas: CEDES, v. 36, n. 133, p. 891-908, 2015.

MACEDO, Elizabeth. Base Nacional Comum para currículos: Direitos de aprendizagem e desenvolvimento para quem? Educação \& Sociedade, Campinas: Unicamp, v. 36, n. 133, p. 891-908, 2015.

MACEDO, Elizabeth. Por uma leitura topológica das políticas curriculares. Arquivos Analíticos de Políticas Educativas, Arizona: Arizona State University, v. 24, n. 26, 2016.

MOREIRA, Antônio Flávio Barbosa. Os Parâmetros Curriculares Nacionais em questão. Educação \& Realidade, Porto Alegre: UFRGS, v. 21, n. 1, p. 9-22, 1996.

MOUFFE, Chantal. Sobre o Político. São Paulo: WMF Martins Fontes, 2015.

MOUFFE, Chantal. La paradoja democrática: El peligro del consenso en la política contemporánea. Barcelona: Gedisa, 2016.

PERONI, Vera Maria Vidal; CAETANO, Maria Raquel. O público e o privado na educação: Projetos em disputa? Retratos da Escola, Brasília: Esforce, v. 9, n. 17, p. 337-352, 2015.

SPINELLI JR., Ronaldo; CÁSSIO, Fernando L. A construção do currículo nacional e o conteúdo segundo professores de Química brasileiros. Enseñanza de las Ciencias, Vigo: Educación Editora, v. 35, n. extra, p. 5511-5516, 2017.

XIMENES, Salomão; CÁSSIO, Fernando. Uma Base em falso. Nexo Jornal, São Paulo, 11 abr. 2017. Disponível em: <www.nexojornal.com.br/ensaio/2017/Uma-Base-em-falso>. Acesso em: 20 mai. 2018. 